\title{
PNEUMONECTOMY WITH IMMEDIATE THORACOPLASTY IN THE TREATMENT OF PULMONARY TUBERCULOSIS
}

\author{
BY \\ GORDON CRUICKSHANK AND EL PAPAMICHAEL \\ From the Leicester Thoracic Surgical Unit
}

(RECEIVED FOR PUBLICATION OCTOBER 22, 1951)

This is a preliminary report of 15 cases of pulmonary tuberculosis treated by pneumonectomy and immediate thoracoplasty.

Though lung resection in the treatment of pulmonary tuberculosis has become a relatively safe operation as regards the mortality rate, complications are still frequent. In spite of skilful operative technique, careful selection of cases, and the use of antibiotics, the complications of bronchopleural fistula and empyema occur.

Bailey, Glover, and O'Neill (1949) reported 202 cases of lung resection for pulmonary tuberculosis, of which 102 were operated on without streptomycin and 100 under streptomycin cover. Of the 102 cases which were operated on without streptomycin, 27 died, 13 developed an empyema, 14 a bronchopleural fistula, and only 49 remained well with negative sputa. Of the other 100 cases treated with streptomycin, 16 died, three developed an empyema, four a bronchopleural fistula, and 77 remained sputum-negative.

Moore, Murphy, and Elrod (1949) reported 74 cases with six deaths (8\%), four empyemas (5\%), four bronchopleural fistulae (5\%), with 64 conversions of sputum.

Selikoff and Tchertkoff (1949) in 125 cases reported 20 deaths (16\%), 13 empyemas $(10 \%), 12$ bronchopleural fistulae $(9 \%)$, and 96 conversions of sputum. Holmes Sellors and Hickey (1949) in 78 cases had 11 deaths (14\%), five empyemas $(6 \%)$, and five bronchopleural fistulae.

Day, Tuttle, O'Brien, Hampton, and Jackson (1950) in 202 cases reported 25 deaths (12\%), 27 empyemas (13\%), and 27 bronchopleural fistulae (13\%).

In the Leicester Chest Unit, in 100 cases of resection for pulmonary tuberculosis followed up for a period of six months to three years, there were six deaths, eight empyemas, seven bronchopleural fistulae, and 87 remained sputum-negative. In these 100 cases are included three pneumonectomies which had an immediate thoracoplasty (one-stage operation) without any post-operative complications. Thus the complications of empyema and bronchopleural fistula have been diminished since streptomycin became available. But still these post-operative complications are the main hazards in resection for pulmonary tuberculosis.

The fate of the pleural space after pneumonectomy was the main concern in the early days of lung resection. The first pneumonectomy was done on October 10, 1911 , for a malignant growth of the lung by Kümmell. Kümmell did a tourniquet pneumonectomy with a thoracoplasty at the same time, and closed the wound by 
tamponage. This patient died six days after the operation. The same operation was tried by Meyer (1909) and Hinz (1923) with the same fatal results. The first successful pneumonectomy combined with a thoracoplasty at the same time was done by Graham and Singer (1933) in a patient suffering from carcinoma of the lung.

Other surgeons considered that it would be better if they reduced the hemithorax space by a thoracoplasty first, and after a period of time performed a pneumonectomy. Such attempts were made first by Nissen (1931) and later by Haight (1934) on benign lesions with successful results.

It seems logical that if after a pneumonectomy one could obliterate the hemithorax very rapidly, then the possibility of a bronchopleural fistula or an empyema would be slight. When thoracoplasty is performed after pneumonectomy for tuberculosis it has two main aims, the first to prevent excessive mediastinal shift and the second to obliterate the pleural space.

From our experience we believe that while the first object is often achieved the obliteration of the pleural space is often far from complete, despite adequate thoracoplasty, because of the rigidity of the fibrinous membrane lining the pneumonectomy space ; in other words, a thoracoplasty as usually performed three to six weeks after pneumonectomy does little to prevent the development of an empyema or a bronchopleural fistula.

The following cases illustrate the above points.

\section{CASE RePorts}

Case 1.-The patient, a man aged 38, had a right upper and middle lobectomy carried out for fibrocavernous tuberculosis on September 7, 1950. He later developed an empyema and a bronchopleural fistula, with spread of disease into the remaining lobe. On December 16 a secondary pneumonectomy was done, removing the right lower lobe. On January 11, 1951, a post-pneumonectomy thoracoplasty was done, removing the first to the eighth ribs. At that operation a small air leak from the region of the bronchial stump could be seen. The patient was feeling well, when on March 4 he had two rigors and foul-smelling pus was found in the space under the thoracoplasty. On March 9 a skin flap drainage of the empyema was performed. This patient has been well since. All his sputum cultures since the secondary pneumonectomy have remained negative.

Case 2.-On September 7, 1950, a right pleuropneumonectomy was performed on this patient, a man aged 23, for "destroyed lung." Eighteen days afterwards a bronchial fistula developed, and on September 27 a post-pneumonectomy thoracoplasty and drainage of the space was performed. The first to the ninth ribs were removed. During this operation a fistula of the bronchial stump was found and was closed by interrupted thread stitches. The drainage tube was removed on October 10. He was feeling well, when on March 3, 1951, he started coughing up persistent frothy sputum-mostly at night or when lying down. An air space corresponding to the perimediastinal space shown in a radiograph was found with a needle. Investigation showed the presence of a bronchopleural fistula, and a skin flap drainage of the empyema was performed on March 20. Post-operative bronchoscopy revealed a very large bronchial fistula. This patient feels well now, and all his post-operative cultures have been negative since pneumonectomy.

On both the above cases an extensive post-pneumonectomy thoracoplasty failed to obliterate the pneumonectomy space and to control the bronchopleural fistula. In 
the second case an extensive thoracoplasty was done only 20 days after a pneumonectomy. In both a space was left under the thoracoplasty; the fistulae did not close and the subsequent empyema eventually had to be drained by skin flap drainage.

As a result of these experiences, we thought that the way by which one could succeed in obtaining a complete and rapid obliteration of the hemithorax after a pneumonectomy was to perform a thoracoplasty at the same time. In planning such an operation we were concerned with the respiratory instability which might follow extensive decostalization and with the shock which might result. These fears proved groundless.

TECHNIQUE

The patient is placed in the head down/face down position. A thoracoplasty incision is made. The sixth rib is resected subperiosteally. If the exposure is not good it is possible to remove another rib, usually the seventh, according to the exposure needed. The removal of two ribs is preferable, especially when it is intended to perform an immediate thoracoplasty at the end of the pneumonectomy. Even if at the end of pneumonectomy it is considered advisable not to proceed with a thoracoplasty, there is no difficulty in closing the thoracic wall in the majority of cases. In all pneumonectomies for tuberculosis the lung is stripped extrapleurally. After the pneumonectomy has been completed the condition of the patient is carefully assessed, and if all is well thoracoplasty is then carried out.

In cases where we decide to proceed with a thoracoplasty we remove as many ribs as is necessary to accomplish a complete obliteration of the hemithorax space. Usually the removal of the second to the seventh ribs is enough. In four cases it was found necessary to remove the eighth rib. The number of ribs which must be removed depends upon the position of the diaphragm. In cases where a pneumoperitoneum has been induced before surgery seven ribs usually will suffice. Normally the second to the sixth ribs are resected from the transverse process, which is left intact, to the anterior axillary line. Only the back end of the seventh is removed to allow the scapula to fall in. If it is necessary to remove the eighth rib then a longer portion of the seventh is resected. When the thoracoplasty is completed a drainage tube is placed through the ninth intercostal space posteriorly and is connected with a suction pump. A tightly strapped pad is placed in the axilla to control the paradoxical movement and help obliteration of the space. The drainage tube is removed in 48 hours.

\section{INDICATIONS}

We feel that in every case where a pneumonectomy is indicated for tuberculosis a thoracoplasty should, if possible, be done immediately after the main operation. One cannot forecast the possibility of performing this one-stage combined operation beforehand. The decision must be taken at the termination of pneumonectomy. We are strict in evaluating the condition of the patient. In one case after a pneumonectomy the operation was interrupted for 10 minutes in order to give time for the patient to improve ; in another thoracoplasty was not performed owing to difficulty with the transfusion during the operation.

We prefer to do this combined operation whenever it is possible in patients aged 30 and over, and especially on patients aged more than 40, in order to avoid a possible second operation later and so to eliminate any further risk.

\section{CAse Reports}

Case 3.-This patient, a woman aged 41 , was subjected to resection because of extensive unilateral fibrocavernous disease with large haemoptyses. A left pneumonectomy 
with a thoracoplasty was done on December 5, 1950. For the thoracotomy the fifth and sixth ribs were resected. The lung was extensively diseased and was stripped extrapleurally throughout. After the lung was removed the third, fourth, and seventh ribs were removed from the transverse process to the anterior axillary line. A segment of the back end of the second rib was removed to allow it to fall in. An intercostal drainage tube was put through the ninth intercostal space posteriorly, which was later connected with a suction pump and removed 48 hours later. This patient made a satisfactory recovery and all the post-operative sputum cultured remained negative.

Case 4.-A woman aged 40 had a left pleuropneumonectomy on February 4, 1951, followed by an immediate thoracoplasty. In this case after the lung had been removed the second, third, fourth, fifth, seventh, and eighth ribs were resected, the sixth being removed at the time of thoracotomy. This patient had a smooth post-operative course and the sputum has been converted since the operation.

Case 5.-A woman aged 21 was diagnosed as having pulmonary tuberculosis in 1949 , and had been since then under observation and treatment in a sanatorium. A radiograph taken on August 9, 1949, showed bilateral tuberculosis with large cavities in the left upper lobe. She was put on postural retention. On March 29, 1950, a right artificial pneumothorax was induced. In November, 1950, a pleural effusion formed on the left side. She was admitted to our clinic on February 23, 1951, for left pneumonectomy. Radiographs on admission showed a satisfactory right artificial pneumothorax, large cavities in the left upper lobe, and disease in the left apical segment of the lower lobe. Her general condition was good and sputum was positive. Her vital capacity was 1,000 ml. On March 27, 1951, a left pleuropneumonectomy was done with an immediate thoracoplasty. For the thoracotomy the fifth and sixth ribs were removed. After the lung resection the second, third, fourth, seventh, and eighth ribs were resected. This patient had a remarkably satisfactory post-operative course without shortness of breath. Refills to maintain the right A.P. have been continued and at the present time she is very well.

Fifteen patients have been subjected to a pleuropneumonectomy and thoracoplasty in one stage for pulmonary tuberculosis (Table I). There has been no mortality or morbidity. All the patients tolerated this one-stage operation well. No patient developed empyema or bronchopleural fistula and all have post-operative negative sputum cultures. All wounds healed by first intention. These patients could cough satisfactorily post-operatively and the paradoxical respiration was minimal. Indeed, we formed the opinion that they often had a smoother postoperative course than patients who had had only a pneumonectomy without thoracoplasty. This opinion was confirmed by the nursing staff. The supporting pad is removed after about 14 days. The movement of the shoulder is maintained surprisingly well. Deformity is not great and in a well-built subject is slight. The aftercare of these patients has not given rise to any special problems.

Some of our observations coincide with those of Iverson and Skinner (1950), who reported 10 cases of this combined operation, of which seven were done for pulmonary tuberculosis and three for other diseases (two carcinoma, one lung abscess and pulmonary cyst). Iverson and Skinner had one case with an empyema which was detected four weeks after the operation on a patient suffering from carcinoma. In this case the second and first ribs were left in situ. The empyema was small and healed easily with a tube drainage. In a second case, a patient suffering from tuberculosis developed signs of bronchopleural fistula two weeks after the combined operation, but at a second operation in which the anterior segments of the second to 
TABLE I

Results of One-stage Pneumonectomy and Thoracoplasty in 15 Cases

\begin{tabular}{|c|c|c|c|c|c|c|c|c|c|c|}
\hline \multicolumn{2}{|c|}{ Case } & Sex & Age & Side & $\begin{array}{l}\text { Indication for } \\
\text { Pneumonectomy }\end{array}$ & $\begin{array}{c}\text { Pre- } \\
\text { operation } \\
\text { Sputum }\end{array}$ & $\begin{array}{c}\text { Date } \\
\text { of Opera- } \\
\text { tion }\end{array}$ & $\begin{array}{c}\text { No. of } \\
\text { Ribs } \\
\text { Removed }\end{array}$ & $\begin{array}{l}\text { Compli- } \\
\text { cations }\end{array}$ & $\begin{array}{c}\text { Movement } \\
\text { of } \\
\text { Arm }\end{array}$ \\
\hline 1 & A.K. & $\mathrm{F}$ & 41 & L. & $\begin{array}{c}\text { Recurrent severe } \\
\text { haemoptyses }\end{array}$ & Positive & $5 / 12 / 50$ & $\begin{array}{c}3-7 \\
\text { Back end }\end{array}$ & None & Good \\
\hline 2 & J.G. & $\mathbf{M}$ & 35 & L. & Destroyed lung & ,, & $20 / 12 / 50$ & $\begin{array}{c}\text { of } 2 \mathrm{nd} \\
3-7 \\
\text { Back end } \\
\text { of } 2 \text { nd }\end{array}$ & , & ," \\
\hline 3 & N.F. & F & 28 & R. & Destroyed lung & , & $3 / 1 / 51$ & $2-8$ & ," & ," \\
\hline 4 & A.L. & $\mathbf{F}$ & 21 & $\mathrm{R}$. & $\begin{array}{l}\text { Destroyed lung } \\
\text { Diabetes }\end{array}$ & ,", & $31 / 1 / 51$ & $2-7$ & ," &, \\
\hline 5 & H.C. & $\mathbf{M}$ & 46 & R. & $\begin{array}{l}\text { Extensive disease } \\
\text { whole lung }\end{array}$ & ,, & $1 / 2 / 51$ & $2-7$ & ", & , \\
\hline 6 & H.O. & 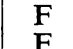 & $\begin{array}{l}40 \\
50\end{array}$ & L. & Destroyed lung & ", & $14 / 2 / 51$ & $\begin{array}{l}2-8 \\
3-8\end{array}$ & , & " \\
\hline 8 & K.T. & $\mathbf{M}$ & 23 & L. & $\begin{array}{c}\text { Extensive disease } \\
\text { whole lung }\end{array}$ & ," & $27 / 2 / 51$ & $2-7$ & ,", & , \\
\hline 9 & C.M. & M & 24 & $\mathbf{R}$. & Destroyed lung & , & $14 / 3 / 51$ & $2-7$ & , & , \\
\hline 10 & F.L. & $\mathbf{M}$ & 34 & R. & $\begin{array}{c}\text { Cavities in right } \\
\text { upper and lower } \\
\text { lobes }\end{array}$ & ,", & $20 / 3 / 51$ & $2-7$ & ," & ," \\
\hline $\begin{array}{l}11 \\
12\end{array}$ & B.G. & $F$ & 21 & L. & Destroyed lung & , & $27 / 3 / 51$ & $2-8$ & , & ", \\
\hline $\begin{array}{l}12 \\
13\end{array}$ & J.S. & $\mathrm{M}$ & 20 & L. & Extensive disease & ,, & $18 / 4 / 51$ & $2-7$ & ,", & ," \\
\hline 14 & F.K. & $\mathbf{M}$ & 42 & $\mathrm{R}$. & Destroyed lung & ," & $10 / 5 / 51$ & $2-7$ & ," & ", \\
\hline 15 & G.W. & $\mathrm{F}$ & 30 & $\mathbf{R}$. & Extensive disease & ," & $21 / 6 / 51$ & $2-7$ & ," & ", \\
\hline
\end{tabular}

the fifth ribs were resected the pleural space was entered and the " residual pleural cavity was found to be small and covered with clean granulations, and contained small amounts of clotted fibrin and a small amount of amber fluid." The cavity was drained and healed easily.

Iverson and Skinner in some cases do not remove the second rib. We feel it desirable to remove it in most cases in order to be certain of obliterating the space. We have allowed the intercostal structures to lie across the mediastinum and have made no attempt to approximate them.

Bickford, Edwards, Esplen, Gifford, Mair, and Thomas (1951) do a more limited thoracoplasty, the aim being to reduce the size of the space rather than to obliterate it.

Though the duration of follow-up in our cases is very short for any final assessment, we feel that this combined operation must reduce the possibility of empyema and bronchial fistula after pneumonectomy very considerably and that its use is therefore justified.

\section{SUMMARY}

Pneumonectomy for pulmonary tuberculosis may be complicated by empyema or bronchial fistula, even when post-resection thoracoplasty has been performed.

The technique of combined pneumonectomy and thoracoplasty is described and results in 15 cases given. The aim is to secure rapid obliteration of the pleural space. 


\section{BiBLIOGRAPHY}

Bailey, C. P., Glover, R. P., and O’Neill, T. J. E. (1949). J. thorac. Surg., 18, 36.

Bickford, B. J., Edwards, F. R., Esplen, J. R., Gifford, J. H., Mair, A. M., and Thomas, O. F. (1951). Thorax, 6, 25.

Crafoord, C. (1938). Acta chir. scand., Suppl. 54.

Day, J. C., Tuttle, W. M., O’Brien, E. J., Hampton, F., and Jackson, T. L. (1950). J. thorac. Surg., 20,854 .

Graham, E. A., and Singer, J. J. (1933). J. Amer. med. Ass., 101, 1371.

Haight, C. (1934). Surg. Gynec. Obstet., 58, 768.

Hinz, R. (1923). Arch. Klin. Chir., 124, 104.

Iverson, R. K., and Skinner, H. L. (1950). J. thorac. Surg., 19, 491.

Kümmell, H. (1911). Verh. dtsch. Ges. Chir., 40, 147.

Meyer, W. (1909). J. Amer. med. Ass., 53, 1978. Quoted by Crafoord (1938).

Moore, J. A., Murphy, J. D., and Elrod, P. D. (1949). J. thorac. Surg., 18, 45.

Nissen, R. (1931). Zbl. Chir., 58, 3003.

Selikoff, I. J., and Tchertkoff, I. G. Quoted by Sarot, I. A. (1949). Thorax, 4, 173.

Sellors, T. H., and Hickey, M. D. (1949). Ibid., 4, 82. 